\title{
Permanent hole burning with a diode laser: excited-state dynamics of bacteriochlorophyll in glasses and micelles
}

\author{
H. van der Laan, H. E. Smorenburg, Th. Schmidt, and S. Völker \\ Center for the Study of Excited States of Molecules, Huygens en Gorlaeus Laboratories, University of Leiden, \\ 2300 RA Leiden, The Netherlands
}

Received October 21, 1991; revised manuscript received December 27, 1991

\begin{abstract}
A temperature- and current-controlled diode laser at $\sim 780 \mathrm{~nm}$ was used to perform permanent hole-burning experiments on the $S_{1} \leftarrow S_{0} 0-0\left(Q_{y}\right)$ transition of bacteriochlorophyll a (BChl a) in amorphous hosts. Hole widths were obtained for the glass triethylamine (TEA) between 0.4 and $15 \mathrm{~K}$, for micelles of the detergent lauryldimethylamine $N$-oxide (LDAO) between 1.2 and $4.2 \mathrm{~K}$, and for wet and dry $\mathrm{CCl}_{4}$ at $1.2 \mathrm{~K}$. The homogeneous linewidth, $\Gamma_{\text {hom }}$, of BChl a in TEA follows a $T^{1.3 \pm 0.1}$ dependence at temperatures $T<7 \mathrm{~K}$, whereas at $T \approx 7 \mathrm{~K} \mathrm{a}$ crossover to an exponential dependence with an activation energy of $33 \pm 3 \mathrm{~cm}^{-1}$ is observed. The results, when compared with those obtained for free-base porphin in the same glass, suggest that a lowfrequency mode of TEA is responsible for the dephasing. From the experiments on micelles conclusions are drawn about the molecular conformations of $\mathrm{BChl} a$ in the detergent.
\end{abstract}

\section{INTRODUCTION}

Pigments of photosynthetic purple bacteria such as bacteriochlorophylls and bacteriopheophytins absorb light in the near IR, a spectral region that was not easily accessible by lasers until recently. Furthermore, the absorption bandwidths of these pigments in any solvent are very broad, of the order of a few hundred inverse centimeters, even at liquid-helium temperatures. The homogeneous linewidth, and therefore the excited-state dynamics, has remained a puzzle for a long time. Site-selection spectroscopy and hole burning, which are powerful highresolution laser techniques, allow one to determine both the vibrational frequencies of ground and excited electronic states ${ }^{1}$ and the dephasing and the relaxation processes of such systems. ${ }^{2}$

Bacteriochlorophyll a ( $\mathrm{BChl}$ a) is a magnesiumtetrahydroporphyrin derivative with an additional fifth ring attached to one of the four pyrrole rings and an alltrans-phytyl chain. The $S_{1} \leftarrow S_{0} 0-0\left(Q_{y}\right)$ transition maximum in solvents such as ether and methanol at room temperature lies at $\sim 770 \mathrm{~nm},{ }^{3}$ whereas $\mathrm{BChl}$ a-protein complexes absorb further to the red; e.g., the antenna complexes absorb at $800-850 \mathrm{~nm},{ }^{4}$ and the primary donor in the reaction center absorbs at $870 \mathrm{~nm} .^{5}$ Many broadband absorption and fluorescence spectra of monomeric and oligomeric $\mathrm{BChl}$ a at room temperature have been reported. $^{6-8}$ Fluorescence lifetimes have also been published, but no reliable values had been obtained until recently because of the poor detection sensitivity in the near IR and the low time resolution. ${ }^{9}$

Although some site-selection spectra and hole-burning results at liquid-helium temperature have been published for plant chlorophylls absorbing at $\sim 670 \mathrm{~nm},{ }^{10,11}$ only a few data are available for $\mathrm{BChl}$ a in glassy hosts. ${ }^{12}$ The only hole-burning research, to our knowledge, that has been reported is for BChl a in diisoamyl ether. ${ }^{12}$ The hole widths, however, were laser limited to $\sim 1 \mathrm{~cm}^{-1}$, and no information was given about the dynamics.
Since BChl a in glasses absorbs at approximately 770 $780 \mathrm{~nm}$, we thought that a temperature- and currentcontrolled single-mode semiconductor-diode laser would be suitable for hole-burning experiments in this system. Its bandwidth is almost 3 orders of magnitude smaller than that of a broadband dye laser, and its scanning range covers $\sim 200 \mathrm{GHz}$. These characteristics, together with its low cost and simplicity, make it an ideal instrument for such experiments. A disadvantage, however, is the narrow wavelength region in which it can be operated, in our case $\sim 780 \pm 5 \mathrm{~nm}$ (more details are give in Subsection 2.B).

Here we report a study by site-selection spectroscopy and permanent hole burning of $\mathrm{BChl}$ a in various amorphous hosts at low temperatures in the near IR. The vibrational frequencies of the first excited singlet state $S_{1}$ up to $\sim 1600 \mathrm{~cm}^{-1}$ above the origin were determined and compared with data from the literature (see Subsection 3.A). The results for optical dephasing of the $S_{1} \leftarrow S_{0}$ 0-0 transition of BChl a in the glass triethylamine (TEA) between 0.4 and $15 \mathrm{~K}$ are discussed in Subsection 3.B. Its behavior is found to be similar to that of free-base porphin $\left(\mathrm{H}_{2} \mathrm{P}\right)$ in the same host. Both $\mathrm{BChl}$ a and $\mathrm{H}_{2} \mathrm{P}$ in TEA show a $T^{1.3 \pm 0.1}$ dependence of $\Gamma_{\text {hom }}$ for $T<7 \mathrm{~K}$ and a deviation from this power law toward an exponential $T$ dependence at higher temperatures (see Subsection 3.B).

Since pigment-protein complexes of photosynthetic compounds are often isolated from the membrane by solubilization with detergents, we were interested in knowing to what extent the detergent may influence the guest-host interactions. For this purpose we dissolved $\mathrm{BChl}$ a in aqueous solutions of the detergent lauryldimethylamine $N$-oxide (LDAO) at various concentrations. LDAO forms micelles that are hydrophylic to the outside and hydrophobic to the inside. $\mathrm{BChl}$ a, being insoluble in water, resides in the inner part of the micelles. The homogeneous linewidth and its temperature dependence were determined for these micellar systems between 1.2 and $4.2 \mathrm{~K}$. The results are discussed in terms of aggregation effects 


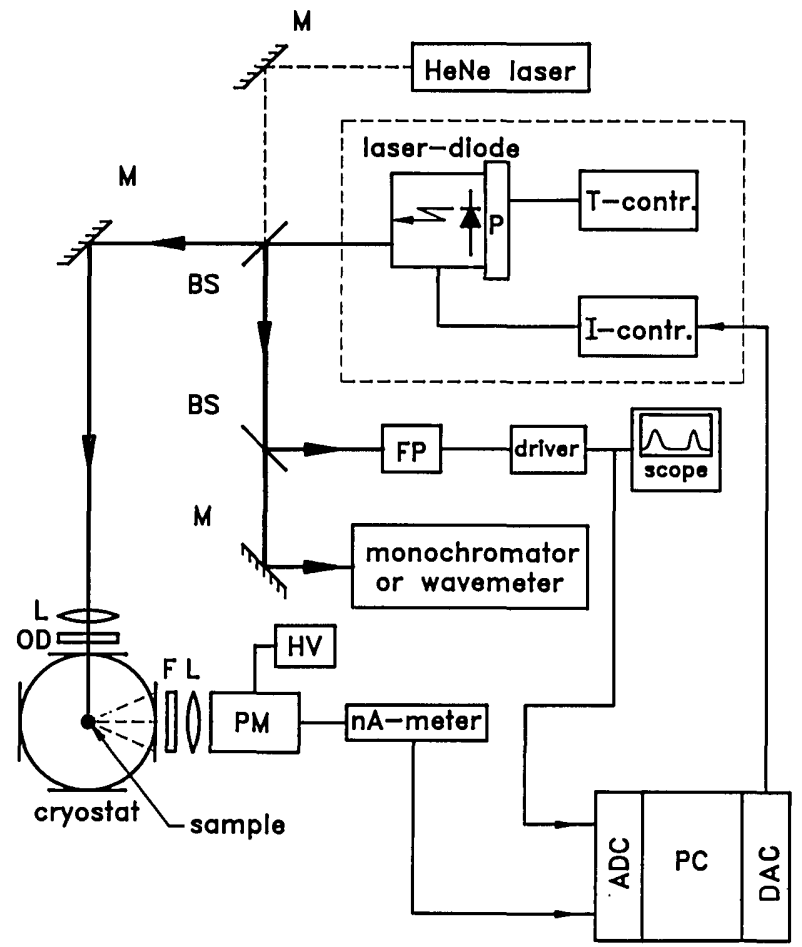

(a)

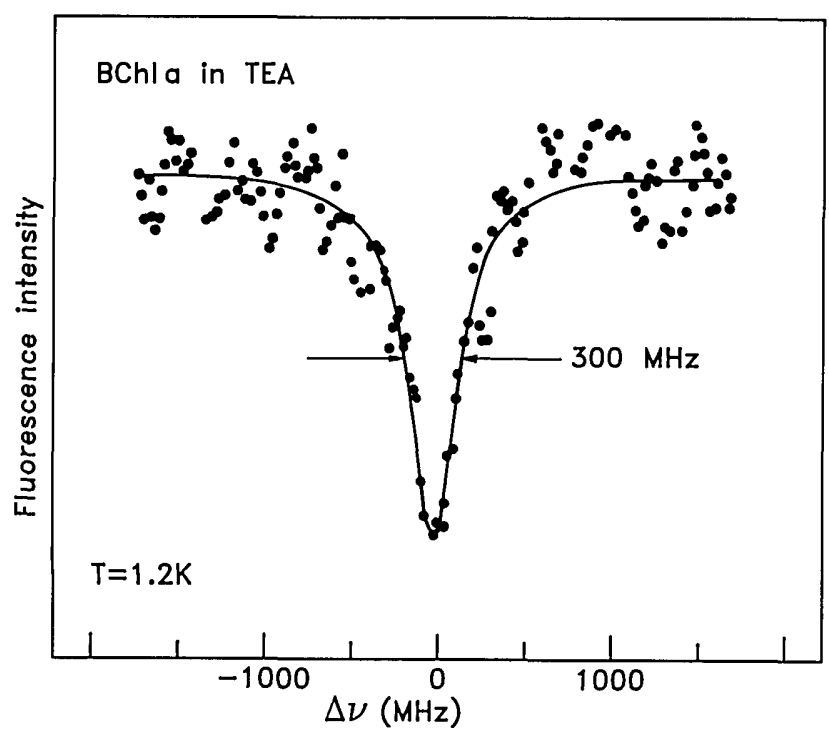

(b)

Fig. 1. (a) Experimental setup for permanent hole-burning with a temperature- and current-controlled single-mode diode laser. M's, mirrors; T-contr., temperature control; I-contr., current control; P, Peltier element; FP, Fabry-Perot interferometer $(\mathrm{FSR}=1.5 \mathrm{GHz}) ; \mathrm{HV}$, high voltage for the photomultiplier (PM); L's, lenses; F, color filters; BS's, beam splitters; OD, neutral-density filter; PC, personal computer; ADC, analog-to-digital converter; DAC, digital-to-analog converter. (b) Example of a hole burned with the diode laser at $\sim 780 \mathrm{~nm}$ in $\mathrm{BChl}$ a in TEA at $1.2 \mathrm{~K}$.

and conformational changes in Subsection 3.C, and the conclusions are summarized in Section 4.

\section{EXPERIMENT}

\section{A. Sample Preparation}

BChl a extracted from purple bacteria Rhodobacter sphaeroides was either obtained from Sigma (product
B8012) and used without further purification or isolated following a slightly modified method by Iriyama et $a l^{13}$ After BChl a was dissolved in ether to an optical density $\mathrm{OD}=1 / \mathrm{mm}$ at $770 \mathrm{~nm}$, the sample was stored at $-20^{\circ} \mathrm{C}$. For preparation of $\mathrm{BChl} \mathrm{a}$ in a given solvent, first the ether was evaporated and the remaining $\mathrm{BChl}$ a film was dissolved in the desired solvent. Samples for holeburning experiments had a concentration $c \approx 3 \times 10^{-5} \mathrm{M}$ and an $\mathrm{OD} \approx 1$ in a 4-mm-thick cuvette at the maximum of the $Q_{y} 0-0$ band $(\sim 770 \mathrm{~nm})$ at room temperature. For absorption spectra, samples with an $\mathrm{OD} \approx 0.5$ were used. The solvents in our experiments were TEA, the detergent LDAO in water at various concentrations $(30 \%, 10 \%, 1 \%$, and $0.1 \% \mathrm{vol} . / \mathrm{vol}$.$) , and dry and wet carbon tetrachloride$ $\left(\mathrm{CCl}_{4}\right)$. BChl a in TEA was quickly cooled (in $\sim 30 \mathrm{~s}$ ) to liquid-helium temperature. The samples looked cracked and nontransparent.

$\mathrm{BChl} \mathrm{a}$ in the detergent LDAO was prepared as follows: First BChl a was disolved in a LDAO: water mixture and the solution was shaken in an ultrasonic bath for 20 min. The undissolved BChl a was then filtered out and the solution diluted to an $\mathrm{OD} \approx 1$ for a 4 -mm thickness at $770 \mathrm{~nm}$. One hour after the beginning of the preparation, the samples were quickly cooled (in $\leq 30$ s) to liquid-helium temperature. The samples looked cracked and rather milky. We noticed that the preparation procedure and cooling rate are highly critical for getting reproducible hole-burning results.

Dry $\mathrm{CCl}_{4}$ was obtained by adding $10 \mathrm{~g}$ of $\mathrm{CaCl}_{2}$ to $100 \mathrm{~mL}$ of $\mathrm{CCl}_{4}$. After a few days $\mathrm{CCl}_{4}$ was distilled off and stored in contact with molecular sieves (pore size $4 \AA$, Merck 5708) to keep it dry. $\mathrm{BChl}$ a was dried according to the method of Ballschmiter et al. ${ }^{14}$ by means of azeotropic distillation with dry $\mathrm{CCl}_{4}$ under a stream of dry nitrogen. The resulting powder of $\mathrm{BChl}$ a was kept in vacuum $\left[10^{-5}\right.$ bar $\left(7.5 \times 10^{-3}\right.$ Torr $\left.)\right]$ at room temperature for $2.5 \mathrm{~h}$ to remove the residual solvent. $\mathrm{BChl}$ a was finally dissolved in dry $\mathrm{CCl}_{4}$ at a concentration of $3 \times 10^{-5} \mathrm{M}$. Wet $\mathrm{BChl}$ a in $\mathrm{CCl}_{4}$ was prepared by adding $\sim 0.05 \mathrm{~mL}$ of water to $1 \mathrm{~mL}$ of dry $\mathrm{BChl}$ a in $\mathrm{CCl}_{4}$.

$\mathrm{H}_{2} \mathrm{P}$ was dissolved in TEA at a concentration of $6 \times 10^{-5} \mathrm{M}$ and shaken in an ultrasonic bath for approximately 10-15 min. The optical density at the maximum of the $S_{1} \leftarrow S_{0} 0-0$ absorption band at $612 \mathrm{~nm}$ was $\mathrm{OD}=2 \times 10^{-2}$ in a 4 -mm-thick cuvette. The sample was quickly cooled (in $\sim 30$ s) to liquid-helium temperature. Its appearance was similar to that of BChl a in TEA.

\section{B. Diode-Laser Characteristics}

Figure 1(a) shows the experimental setup used for permanent hole burning. The laser diode (Hitachi HL 7806G, double heterostructure) had an output power of $\sim 5 \mathrm{~mW}$ at $780 \mathrm{~nm}$. It was fixed in a mount (ILX Lightwave, LDM 4412) that was connected to a temperature controller (ILX Lightwave, LDT 5910, stability better than $0.1^{\circ} \mathrm{C}$ in $10 \mathrm{~min}$ ). The mount consists of an aluminum plate that functions as a heat sink. The temperature of the plate, measured by a temperature sensor, was varied by a Peltier element. The whole mount was flushed with a small flow of dry nitrogen gas to avoid condensation on the diode when used below room temperature. The injection current through the laser diode was controlled by a stable home-built current supply $\left(\Delta I / I<10^{-5}\right)$, which was con- 


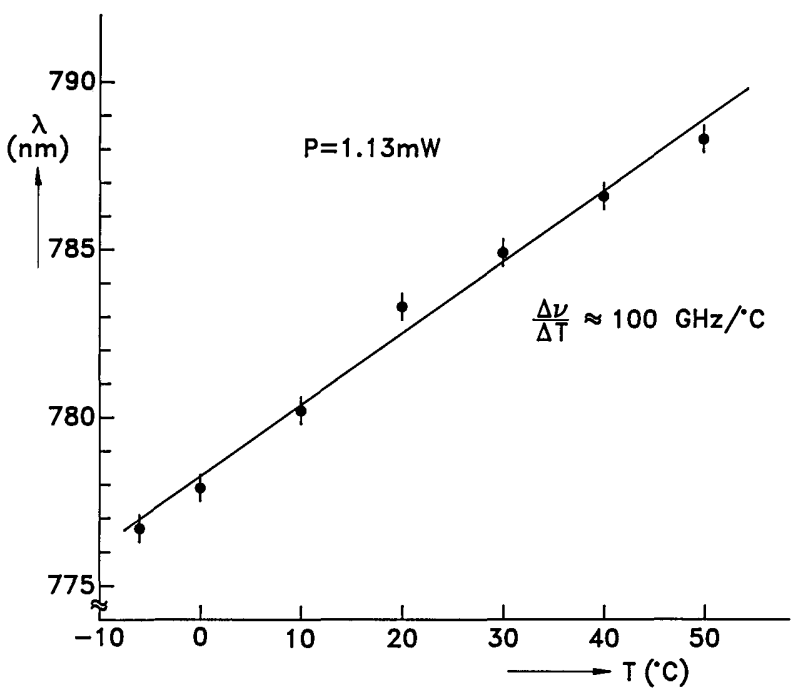

(a)

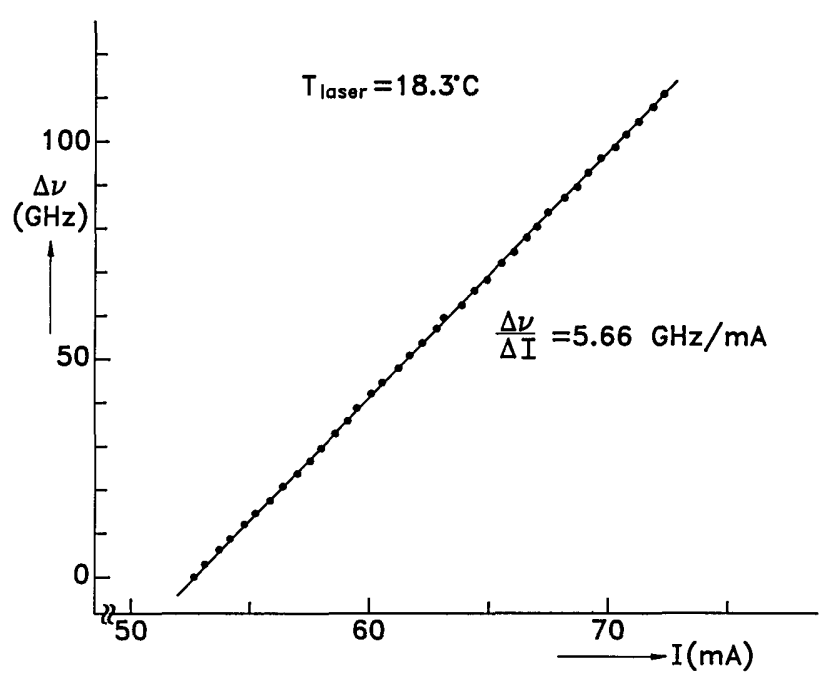

(b)

Fig. 2. (a) Wavelength $\lambda$ of the single-mode diode laser as a function of temperature $T$ measured at constant laser power $(P=1.13 \mathrm{~mW})$. (b) Change in frequency of the single-mode diode laser $\Delta \nu$ as a function of injection current $I$ at constant temperature $\left(T=18.3^{\circ} \mathrm{C}\right)$.

nected to a personal computer through a digital-to-analog converter.

The approximate wavelength of the diode laser was determined by a small monochromator (Jobin Yvon H10 V) with an accuracy of $\sim 0.2 \mathrm{~nm}$, and its mode structure was monitored by a scanning Fabry-Perot étalon (Tropel 240, free spectral range FSR $=1.5 \mathrm{GHz}$ ). To calibrate the laser scan length, we used the same Fabry-Perot étalon but with a fixed distance between the mirrors. The transmission signal through the étalon was fed into the personal computer through an analog-to-digital converter together with the fluorescence signal from the sample.

The diode laser was roughly tuned between 777 and $788 \mathrm{~nm}$ by varying the temperature between $-10^{\circ}$ and $50^{\circ} \mathrm{C}$; the mean change in frequency amounts to $\sim 100 \mathrm{GHz} /{ }^{\circ} \mathrm{C}$ [see Fig. 2(a)]. The tuning is not continuous because mode hops occur every $100-200 \mathrm{GHz} .^{15}$ Scanning in one mode (at $30 \mathrm{GHz} /{ }^{\circ} \mathrm{C}$ ) is possible by slightly changing the temperature. It is more convenient, however, to achieve fine tuning and scanning within a mode by varying the injection current, by which scan rates of $\sim 6 \mathrm{GHz} / \mathrm{mA}$ are obtained [see Fig. 2(b)]. Extremely fast scanning rates may be reached, 4 orders of magnitude faster than those achievable with a mechanically scanned dye or titanium:sapphire laser. ${ }^{16}$ This makes a diode laser ideal for time-resolved hole-burning experiments on a microsecond time scale. ${ }^{17}$

The linewidth of the diode laser, $\Gamma_{\text {laser }}$, was determined in three different ways. The first method is depicted in Fig. 3, where the width $\Gamma_{\text {meas }}$ is plotted as a function of the inverse of the diode laser output power $P .{ }^{18,19}$ This width was measured by means of a fixed Fabry-Perot étalon $(\mathrm{FSR}=1.5 \mathrm{GHz})$ and by slowly scanning the diode laser. $\Gamma_{\text {meas }}$ includes $\Gamma_{\text {laser }}$ and $\Gamma_{\mathrm{FP}}$, the width of the Fabry-Perot transmission peaks. In these experiments the FabryPerot étalon was slightly misaligned to avoid recoupling of the laser light into the cavity, so that $\Gamma_{\mathrm{FP}}$ increased from $\sim 7.5$ to $\sim 60 \mathrm{MHz}$. The data points were fitted with a straight line that extrapolates $\sim 60 \mathrm{MHz}$ for $P \rightarrow \infty$. This value is almost totally given by $\Gamma_{\mathrm{FP}}$ because the linewidth of a diode laser in the limit $P \rightarrow \infty$ approaches $\sim 2 \mathrm{MHz}{ }^{18}$ An additional small contribution to the width might be caused by current and temperature fluctuations, but these would hardly depend on the laser output power and would shift the straight line only vertically. Since both current and temperature are stabilized, this contribution is at most 5-10 MHz. At the average output power used in our experiments $(P \approx 2.50 \mathrm{~mW})$, a linewidth for the diode laser of $\Gamma_{\text {laser }} \approx 45 \mathrm{MHz}$ is obtained from Fig. 3 .

In the second method the laser linewidth was determined by means of a Michelson-type interferometer. The visibility of an interference fringe pattern, $V(\tau)=$ $\left(P_{\max }-P_{\min }\right) /\left(P_{\max }+P_{\min }\right)$, where $P_{\max }$ and $P_{\min }$ are the output power of the interferometer at constructive and destructive interference, respectively, was measured as a

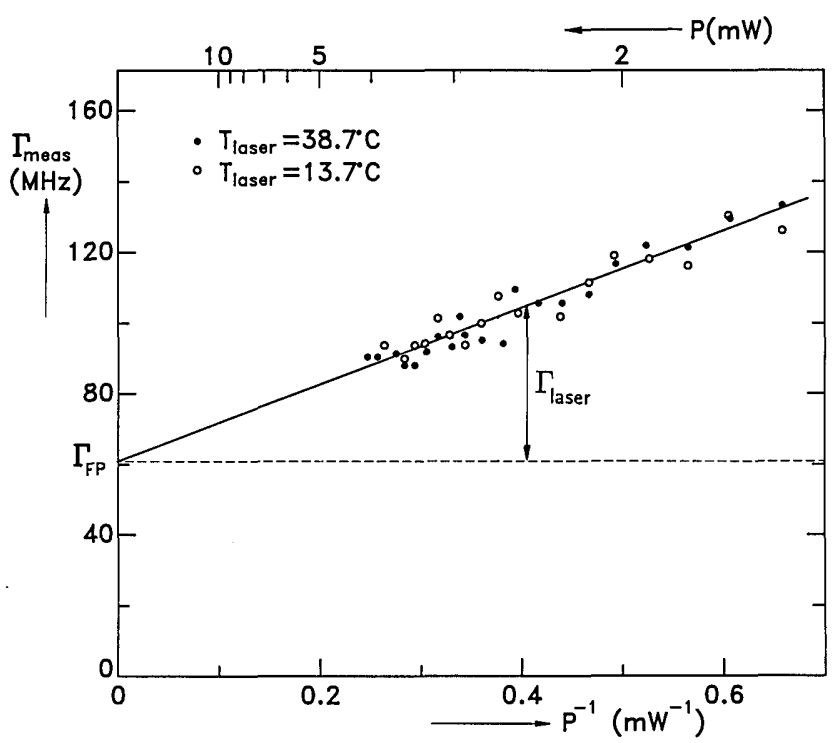

Fig. 3. Determination of the single-mode diode laser linewidth $\Gamma_{\text {laser }}$ with a Fabry-Perot interferometer FP $(F S R=1.5 \mathrm{GHz})$. Measured linewidth $\Gamma_{\text {meas }}$ as a function of the inverse of the laser output power $P . \quad \Gamma_{\text {laser }} \approx 45 \mathrm{MHz}$ was obtained as the difference between $\Gamma_{\text {meas }}$ at an average output power used in the experiments and the width $\Gamma_{\mathrm{FP}}$ (see text). 


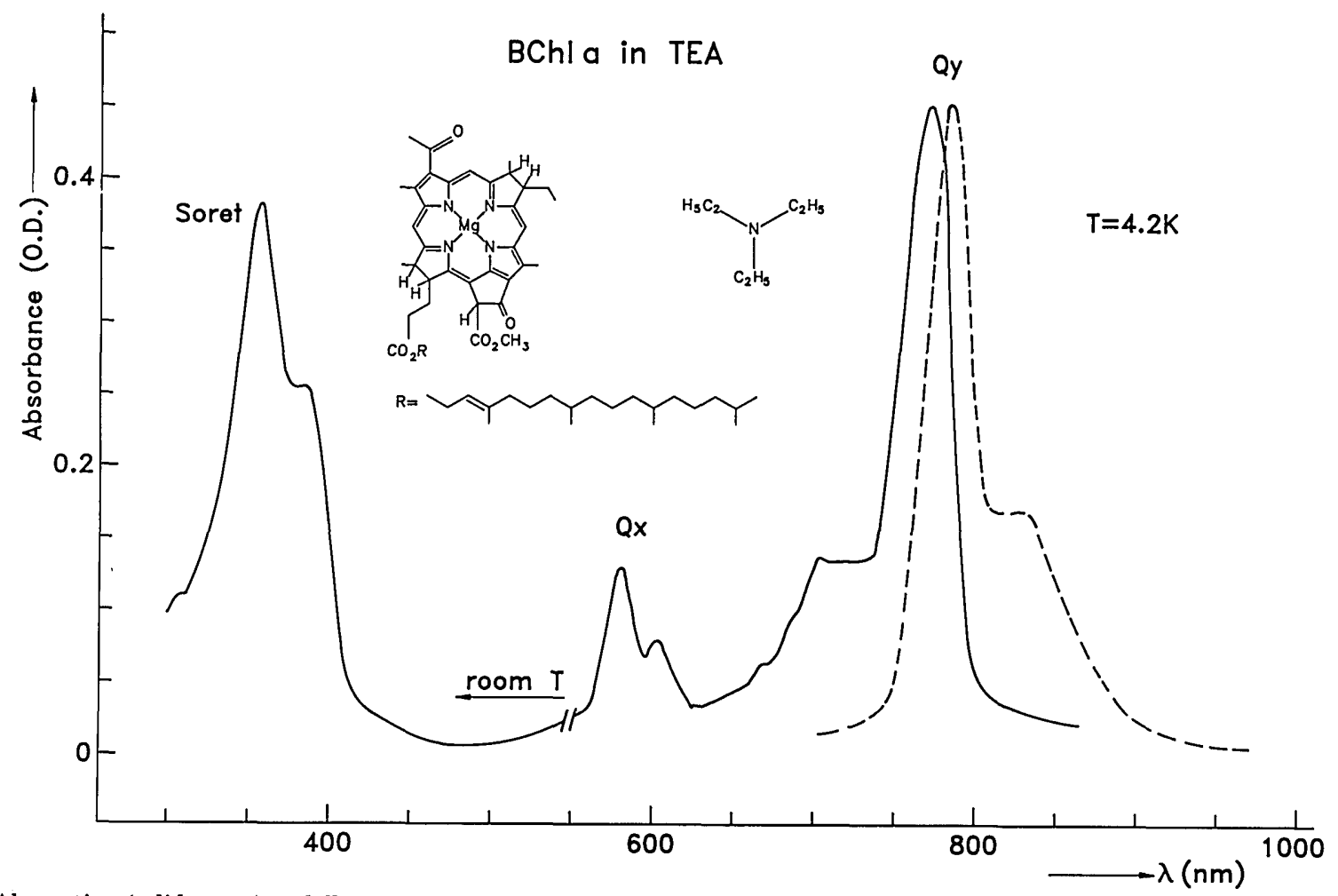

Fig. 4. Absorption (solid curve) and fluorescence (dashed curve) spectra of BChl a in TEA at $4.2 \mathrm{~K}$. The maximum of the $S_{1} \leftarrow S_{0} 0-0$ $\left(Q_{y}\right)$ transition lies at $\sim 775 \mathrm{~nm}$, the wavelength region of the diode laser. Notice that the $Q_{x}$ transition has two peaks (see text). The spectrum of the Soret band at the left was taken at room temperature. Inset: bacteriochlorophyll a and triethylamine.

function of $\tau$, the relative delay time of the two paths of the interferometer. ${ }^{20}$ From this dependence $\Gamma_{\text {laser }} \approx$ $40 \mathrm{MHz}$ was obtained.

In the third method we compared a hole burned and scanned with our diode laser [see Fig. 1(b)] with a similar hole burned with a titanium:sapphire laser (Coherent 899-21, frequency jitter $<500 \mathrm{kHz}$ ). From the difference of the two widths we obtained $\Gamma_{\text {laser }} \approx 50 \mathrm{MHz}$. The somewhat larger values yielded by the first and the third methods are probably caused by long-time jitter effects because the widths were determined over a time of $\sim 1 \mathrm{~min}$. In all the hole-burning experiments we assumed a value $\Gamma_{\text {laser }}=50 \mathrm{MHz}$ for the determination of the homogeneous linewidth (see Subsections 3.B and 3.C).

\section{Spectroscopy and Hole Burning}

Broadband absorption spectra of BChl a in TEA at $4.2 \mathrm{~K}$ (see Fig. 4) were taken by irradiating the sample with a halogen lamp, the light of which was passed through a water filter to remove the IR part of the spectrum. The transmission was detected through a $0.85-\mathrm{m}$ double monochromator (Spex 1402, resolution $\sim 12 \AA$ ) with a nitrogen-cooled photomultiplier (EMI 9684). The intensity of the signal at each wavelength was subsequently divided by that of a reference spectrum of the TEA glass, and the ratio plotted. Broadband fluorescence spectra (dashed curve in Fig. 4) were recorded by exciting the sample into the Soret band with a pulsed nitrogen laser at $337 \mathrm{~nm}$ (Molectron UV-22, repetition rate $\sim 20 \mathrm{~Hz}$ ) and scanning the double monochromator with a resolution of $\sim 4 \AA$. Site-selected fluorescence spectra were obtained by excitation into a vibronic band of the $S_{1} \leftarrow S_{0}$ transition of $\mathrm{BChl}$ a at $716 \mathrm{~nm}$ (see Fig. 5) with a cw titanium:sapphire laser (Coherent 899-21, without intracavity assembly, bandwidth $<0.3 \mathrm{~cm}^{-1}$ ). The spectra were recorded between 750 and $840 \mathrm{~nm}$ with a resolution of $\sim 3 \mathrm{~cm}^{-1}$.

Broad holes (resolution of $\sim 1 \mathrm{~cm}^{-1}$ ) were burned with two types of lasers into the $S_{1} \leftarrow S_{0} 0-0$ transitions of BChl a and $\mathrm{H}_{2} \mathrm{P}$ in glasses. A tunable cw dye laser (SpectraPhysics 375 , bandwidth $\sim 1 \mathrm{~cm}^{-1}$, dye Styryl 8 , amplitude stabilized by an electro-optic modulator to

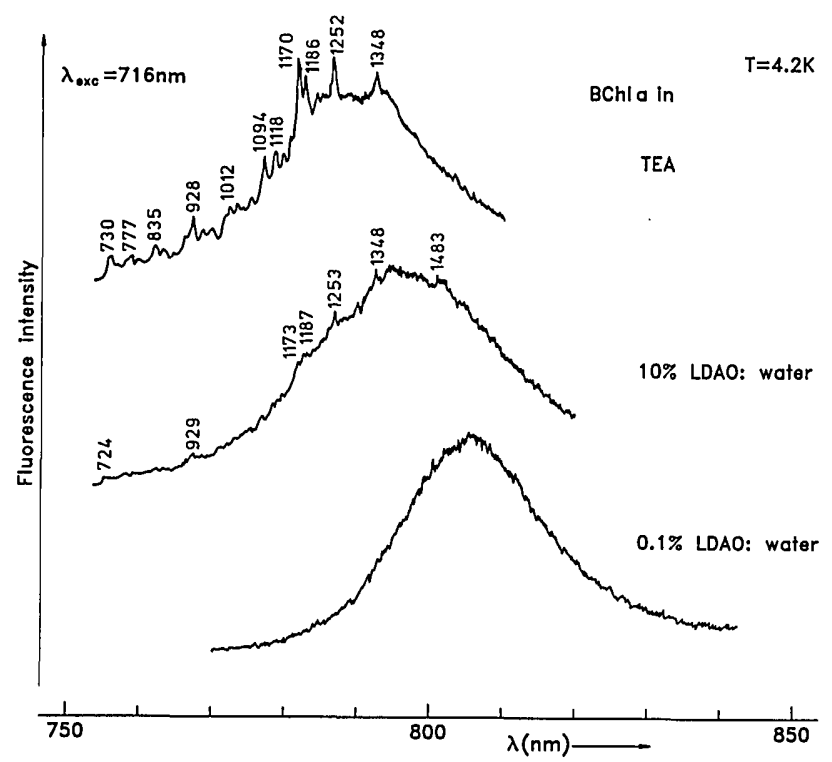

Fig. 5. Site-selected fluorescence spectra of $\mathrm{BChl}$ a in various glasses at $4.2 \mathrm{~K}$, excited at $716 \mathrm{~nm}$. Notice the loss of sharpness in the peaks when going from TEA to $0.1 \%$ LDAO: water (see text). 
$<0.5 \%$ ), pumped by an $\mathrm{Ar}^{+}$laser, was used for $\mathrm{BChl}$ a at $\sim 780-790 \mathrm{~nm}$, whereas a tunable pulsed dye laser (Molectron DL 200, bandwidth $\sim 0.7 \mathrm{~cm}^{-1}$, dye Rhodamine B), pumped by the $\mathrm{N}_{2}$ laser, was used for $\mathrm{H}_{2} \mathrm{P}$ at $\sim 610-620 \mathrm{~nm}$.

Narrow holes were burned in $\mathrm{BChl}$ a with a cw, currentand temperature-controlled, single-mode diode laser at 780-790 nm (see Subsection 2.B). Narrow holes in $\mathrm{H}_{2} \mathrm{P}$ were burned with a cw single-frequency dye laser ${ }^{2}$ (Coherent 599-21, dye Rhodamine 6G, frequency jitter $\leq 2 \mathrm{MHz}$, scan range $30 \mathrm{GHz}$, amplitude stabilized to $<0.5 \%$ ).

The holes were probed by fluorescence excitation spectroscopy in $\sim 100 \mathrm{~s}$. The laser was scanned, attenuated by a factor of 10-100, over the spectral region of the hole, and the fluorescence signal was detected with a cooled photomultiplier (EMI $9658 \mathrm{R}$ ) through a cutoff filter at $\lambda>830 \mathrm{~nm}$ for $\mathrm{BChl}$ a and at $\lambda>645 \mathrm{~nm}$ for $\mathrm{H}_{2} \mathrm{P}$. Hole widths were measured as a function of burning time at various burning powers. The burning fluence densities, $P t / A$, for $\mathrm{H}_{2} \mathrm{P}$ in TEA and for BChl a in TEA, $\mathrm{CCl}_{4}$, and LDAO:water are given in Table 1 . The burning times used in these experiments varied between 2 and $100 \mathrm{~s}$, while the burning powers, depending on the spot size $A$ of the laser on the sample, varied from 1 to $400 \mu \mathrm{W}$, with $A$ varying from 2 to $50 \mathrm{~mm}^{2}$. Notice that the values of $P t / A$ are quite similar for $\mathrm{H}_{2} \mathrm{P}$ and $\mathrm{BChl}$ a in TEA. Also, $\mathrm{BChl}$ a in $30 \%$ and $10 \%$ LDAO:water needed similar burning fluences, but higher fluences were necessary for $1 \%$ and $0.1 \% \mathrm{LDAO}$ : water and $\mathrm{CCl}_{4}$.

The homogeneous linewidth $\Gamma_{\text {hom }}$ was determined from the expression $\Gamma_{\text {hom }}=1 / 2 \Gamma_{\text {hole }}-\Gamma_{\text {laser, }}{ }^{2}$ where $\Gamma_{\text {hole }}$ is the measured hole width extrapolated to the lowest burning fluences and $\Gamma_{\text {laser }}=50 \mathrm{MHz}$ is the diode laser bandwidth. The frequency profile of the latter is Lorentzian.

A conventional ${ }^{4} \mathrm{He}$-bath cryostat was used for temperatures between 1.2 and $4.2 \mathrm{~K}$. The temperature was determined by means of a calibrated carbon resistor and, simultaneously, by the vapor pressure of the helium (with an accuracy of $0.01 \mathrm{~K}$ ). For temperatures below $1.2 \mathrm{~K}$, a ${ }^{3} \mathrm{He}$-glass insert was placed inside the ${ }^{4} \mathrm{He}$-bath cryostat. At $1.2 \mathrm{~K}^{3} \mathrm{He}$ was condensed into the inner cryostat, where it remained liquid for 3-5 h. By reduction of the vapor pressure, temperatures as low as $0.4 \mathrm{~K}$ were reached. The temperature was measured for $T<0.5 \mathrm{~K}$ by a calibrated carbon resistor in contact with the sample and for $T>0.5 \mathrm{~K}$ simultaneously by this resistor and by means of the vapor pressure. The accuracy of the temperature determination was $0.02 \mathrm{~K}^{21}$ Between 4.2 and $20 \mathrm{~K}$ a gasflow cryostat (Leybold-Heraeus) was used. Since in such a cryostat there is only a limited thermal contact between the sample and the cooling gas, the temperature was measured with a resistor in contact with the sample. The temperature of the gas flow was controlled by a homebuilt electronic device. ${ }^{22}$

\section{RESULTS AND DISCUSSION}

A. Absorption and Site-Selected Fluorescence Spectra Absorption and broadband fluorescence spectra of $\mathrm{BChl}$ a in the glass TEA at $4.2 \mathrm{~K}$ between 550 and $950 \mathrm{~nm}$ and an absorption spectrum of the Soret band at room temperature between 300 and $550 \mathrm{~nm}$ are shown in Fig. 4 . The maximum of the $S_{1} \leftarrow S_{0} 0-0\left(Q_{y}\right)$ transition is at
Table 1. Burning Fluence Densities $P t / A$ at Various Temperatures $^{a}$

\begin{tabular}{ccc}
\hline Sample & $T(\mathrm{~K})$ & $P t / A\left(\mathrm{~mJ} / \mathrm{cm}^{2}\right)$ \\
\hline $\mathrm{H}_{2} \mathrm{P}-\mathrm{TEA}$ & 1.2 & $0.15-2.5$ \\
& 4.2 & $0.50-10$ \\
BChl a-TEA & 13 & $10-40$ \\
& 0.5 & $0.14-0.60$ \\
& 1.2 & $0.17-6.3$ \\
BChl a-CCl $_{4}$ & 4.2 & $0.18-5.3$ \\
Dry & 14.3 & $8-80$ \\
Wet & 1.2 & \\
BChl a-LDAO & 1.2 & $1.5-100$ \\
$30 \%$ & & $2.0-75$ \\
& 1.6 & $0.11-1.4$ \\
$10 \%$ & 4.2 & $0.6-3.0$ \\
$1 \%$ & 1.2 & $0.5-2.2$ \\
$0.1 \%$ & 1.2 & $2-60$ \\
& 1.2 & $5.2-25$ \\
& 4.2 & $8-25$ \\
\hline
\end{tabular}

${ }^{a}$ Burning times $t$ were varied between 2 and $100 \mathrm{~s}$, burning powers $P$ from 1 to $400 \mu \mathrm{W}$, and the spot size $A$ of the laser on the sample between 2 and $50 \mathrm{~mm}^{2}$.

$775 \mathrm{~nm}$, whereas the $S_{2} \leftarrow S_{0} 0-0\left(Q_{x}\right)$ transition occurs at $\sim 580 \mathrm{~nm}$. The inhomogeneous width of the $Q_{y}$ band is $\sim 620 \mathrm{~cm}^{-1}$, independent of temperature between room temperature and $4.2 \mathrm{~K}$. The shoulder between 680 and $750 \mathrm{~nm}$ is due to excited-state vibrations of the $S_{1} \leftarrow S_{0}$ transition. The $Q_{x}$ band consists of a larger peak at $\sim 580 \mathrm{~nm}$ and a smaller one at $\sim 610 \mathrm{~nm}$. According to the literature ${ }^{7,23}$ the positions of these two peaks indicate the coordination state of the central magnesium atom. Five-coordinated magnesium species absorb near $580 \mathrm{~nm}$, whereas six-coordinated magnesium species are red shifted to $\sim 610 \mathrm{~nm}^{7}$ Our absorption spectrum indicates that magnesium is predominantly five-coordinated in TEA; the red shoulder suggests the presence of a small amount of a six-coordinated $\mathrm{BChl}$ a species. Thus $\mathrm{BChl}$ a forms complexes with one and two TEA molecules attached to the magnesium atom through their lone electron pair.

The fluorescence spectrum (dashed curve of Fig. 4, not corrected for instrumental wavelength dependence) is mirror symmetric with respect to the absorption spectrum in the $Q_{y}$ region. It shows a Stokes shift of $\sim 200 \mathrm{~cm}^{-1}$. The maximum fluorescence intensity is in the $0-0$ region at $\sim 786 \mathrm{~nm}$, the vibrational region between 820 and $840 \mathrm{~nm}$ being much weaker.

We also investigated site-selected fluorescence spectra of BChl a in TEA and in micelles of LDAO in water at various concentrations at $4.2 \mathrm{~K}$. The spectrum in TEA (top curve, Fig. 5), excited in the $S_{1} \leftarrow S_{0}$ vibronic region of BChl a at $716 \mathrm{~nm}$ and detected in the $S_{1} \leftarrow S_{0} 0-0$ region, shows a well-resolved structure, from which the vibrational frequencies of the $S_{1}$ state (indicated in the figure) were determined. These frequencies are averages of approximately five spectra and are consistent with the values previously reported for this system. ${ }^{12}$ The vibronic structure of the spectrum in 10\% LDAO:water is less pronounced than in TEA (see Fig. 5, middle curve). We have verified, again from approximately five spectra, that the vibrational frequencies are quite similar to those 


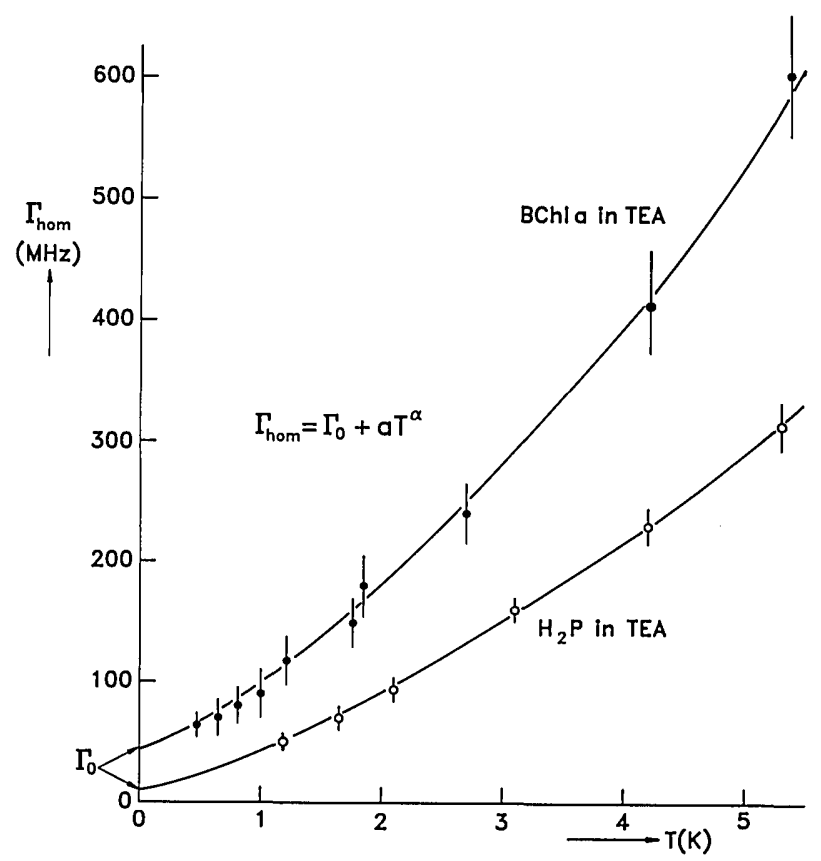

Fig. 6. Homogeneous linewidth $\Gamma_{\text {hom }}$ of the $S_{1} \leftarrow S_{0} 0-0$ transition of $\mathrm{BChl}$ a and $\mathrm{H}_{2} \mathrm{P}$ in TEA as a function of temperature between 0.4 and $5 \mathrm{~K}$. The data on the upper curve (BChl a in TEA) were measured with the diode laser at $\sim 780 \mathrm{~nm}$. The data on the lower curve $\left(\mathrm{H}_{2} \mathrm{P}\right.$ in TEA) were obtained with a singlefrequency dye laser at $\sim 612 \mathrm{~nm}$. The curves are least-squares fits to the equation $\Gamma_{\text {hom }}=\Gamma_{0}+a T^{\alpha}$, where $\Gamma_{0}$ represents the fluorescence lifetime-limited value of the guest and $\alpha \sim 1.35$ (for parameters, see text).

in TEA, which seems to indicate that the $\mathrm{BChl}$ a molecule is not strongly distorted in this micelle. However, in the region around $1000 \mathrm{~cm}^{-1}$ there appear to be more resolved vibrations in TEA than in 10\% LDAO: water. In the spectrum of $\mathrm{BChl}$ a in 0.1\% LDAO:water the vibronic structure has completely disappeared (Fig. 5, bottom curve). We observe further that the $S_{1} \rightarrow S_{0}$ 0-0 fluorescence region shifts to the red by $\sim 20 \mathrm{~nm}$, from $786 \mathrm{~nm}$ in TEA to $805.5 \mathrm{~nm}$ in $0.1 \%$ LDAO: water. This red shift is correlated with a larger Stokes shift, which increases from $\sim 200 \mathrm{~cm}^{-1}$ in TEA to $\sim 320 \mathrm{~cm}^{-1}$ in $0.1 \%$ LDAO: water (not shown).

We attribute the disappearance of the vibronic structure and the larger Stokes shift in the dilute LDAO: water sample to an increase of the electron-phonon coupling. The result of the stronger coupling is a reduced intensity of the sharp zero-phonon line together with an increase of the broad phonon sidebands. We would expect a stronger coupling also to affect the optical dephasing, a subject discussed in Subsection 3.C.

\section{B. Optical Dephasing in Triethylamine Glass}

For the determination of the homogeneous linewidth, $\Gamma_{\text {hom }}$, narrow holes were burned into the $S_{1} \leftarrow S_{0} 0-0$ transition of $\mathrm{BChl} a$ in the glass TEA. The mechanism for hole burning is most probably a reorientation, on excitation, of the central magnesium atom with respect to the axial ligands attached to it, a process similar to that previously observed for a MG-porphin complex in n-octane. ${ }^{24}$ We have compared the results with those obtained for the $S_{1} \leftarrow S_{0}$ 0-0 transition of $\mathrm{H}_{2} \mathrm{P}$ in the same glass, which lies in the visible at $\sim 612 \mathrm{~nm}$. A good fit to the data for both systems below $4.2 \mathrm{~K}$ (see Fig. 6) was obtained with

$$
\Gamma_{\text {hom }}=\Gamma_{0}+a T^{\alpha},
$$

where $\Gamma_{0}=\left(2 \pi T_{1}\right)^{-1}$ is the fluorescence lifetime-limited value reached by extrapolation of $\Gamma_{\text {hom }}$ for $T \rightarrow 0$ and $a$ is a constant that is a measure for the coupling of the guest molecule to the host. The power dependence on temperature in Eq. (1) is thought to be related to the distribution of two-level systems (TLS's) of the glass., ${ }^{2,25}$ We obtained $\Gamma_{0}=45 \pm 5 \mathrm{MHz}, \alpha=1.35 \pm 0.1$, and $a=51 \pm 10 \mathrm{~K}^{-\alpha}$ for $\mathrm{BChl} \mathrm{a}$ in TEA and $\Gamma_{0}=9.5 \pm 2 \mathrm{MHz}, \alpha=1.33 \pm 0.1$, and $a=33 \pm 5 \mathrm{~K}^{-\alpha}$ for $\mathrm{H}_{2} \mathrm{P}$ in TEA. A similar $T^{1.3}$ dependence of $\Gamma_{\text {hom }}$ has been found for many organic glasses up to $4.2 \mathrm{~K}$ and for four systems even up to $\sim 20 \mathrm{~K}^{22}$

The coupling is stronger for $\mathrm{BChl}$ a than for $\mathrm{H}_{2} \mathrm{P}$ in TEA. We believe that this can be attributed, on the one hand, to the fact that $\mathrm{BChl} a$ is a larger molecule than $\mathrm{H}_{2} \mathrm{P}$, with many side groups and a long phytyl chain, whereas $\mathrm{H}_{2} \mathrm{P}$ is an unsubstituted porphin. As a consequence $\mathrm{BChl}$ a has a higher probability to couple to lowfrequency modes of the glass. On the other hand, $\mathrm{BChl}$ a forms a complex with TEA through its central magnesium atom, which probably further enhances the coupling to the host as compared to that for $\mathrm{H}_{2} \mathrm{P}$, which does not form any complex with TEA. Interestingly, both molecules, despite being of quite different sizes, follow the same $\mathrm{T}^{1.3}$ power law at low temperatures. The fluorescence lifetimes derived from the $\Gamma_{0}$ values are $T_{1}=3.5 \pm 1 \mathrm{~ns}$ for $\mathrm{BChl}$ a and $17 \pm 3 \mathrm{~ns}$ for $\mathrm{H}_{2} \mathrm{P}$, which agree well with the lifetimes reported for $\mathrm{BChl}$ a in various organic solvents at room temperature ${ }^{9}$ and for $\mathrm{H}_{2} \mathrm{P}$ in $n$-octane. ${ }^{26}$

Only for a few organic amorphous systems has the homogeneous linewidth $\Gamma_{\text {hom }}$ been measured by means of hole burning at temperatures above $4.2 \mathrm{~K}^{22}$ In order to find out to what degree the $T^{1.3}$ temperature dependence remains valid at higher temperatures, we have extended the experiments of Fig. 6 on BChl a and $\mathrm{H}_{2} \mathrm{P}$ in TEA to $15 \mathrm{~K}$. (Because of the limited scan range of $30 \mathrm{GHz}$ of the single-frequency dye laser, no reliable measurements could be made above $15 \mathrm{~K}$.) Figure 7 is a $\log -\log$ plot of the pure dephasing contribution, $\Gamma_{\text {hom }}-\Gamma_{0}$, as a function of temperature between 0.4 and $15 \mathrm{~K}$, in which the values of $\Gamma_{0}$ are taken from the fits of Fig. 6 . At $T \approx 7 \mathrm{~K}$ the data for both samples start to deviate from a $T^{1.3}$ power law and show a steeper dependence on temperature. The temperature was measured with a resistor in contact with the sample. As a check on the procedure we further redetermined the dephasing of Resorufin in glycerol between 6 and $19 \mathrm{~K}$ and obtained a result in agreement with those previously found in our laboratory. ${ }^{22}$ Apparently the deviation from a $T^{1.3}$ dependence observed for $\mathrm{BChl} a$ and $\mathrm{H}_{2} \mathrm{P}$ in TEA at $T \geq 7 \mathrm{~K}$ is real and is not caused by an erroneous temperature calibration.

The data of Fig. 7 have been fitted with the expression

$$
\Gamma_{\text {hom }}-\Gamma_{0}=\Gamma_{\mathrm{TLS}}+\Gamma_{\mathrm{lib}}=a T^{\alpha}+b \frac{\exp (-E / k T)}{1-\exp (-E / k T)} .
$$

The pure dephasing contribution, $\Gamma_{\text {hom }}-\Gamma_{0}$, consists here of two terms, with the first term taking into account the effect of the TLS [see Eq. (1)] and the second term the effect of localized librational modes, $\Gamma_{\text {lib. }}{ }^{27}$ In Ref. 27, however, the first term was taken as linear in $T$ and not in 


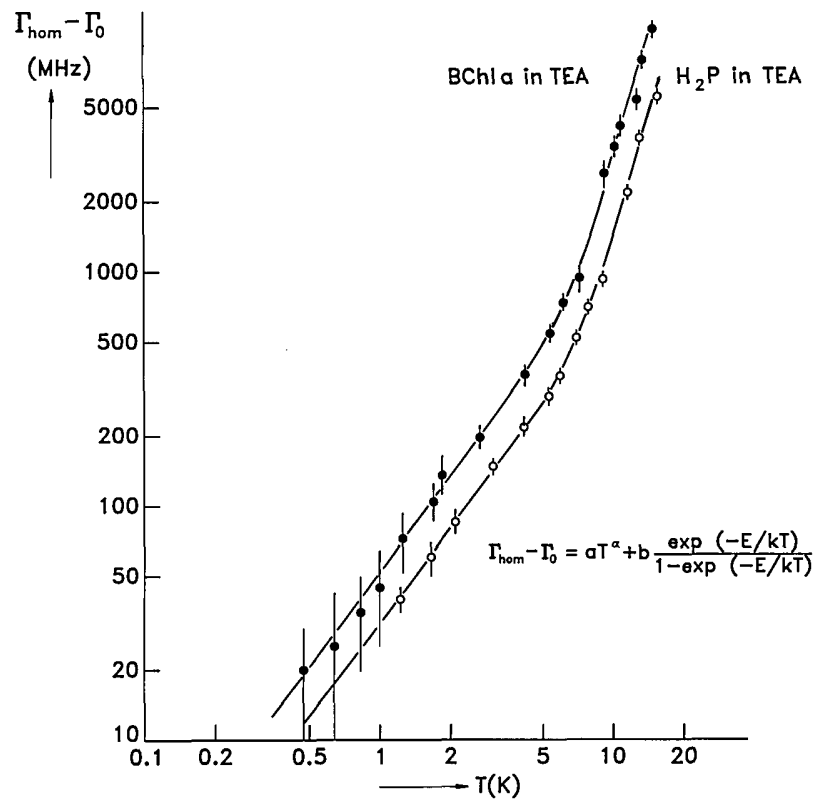

Fig. 7. Log-log plot of the pure dephasing contribution, $\Gamma_{\text {hom }}-\Gamma_{0}$, versus temperature $T$ for $\mathrm{BChl}$ a and $\mathrm{H}_{2} \mathrm{P}$ in TEA between 0.4 and $15 \mathrm{~K}$. The best fit to the data is given by the expression in the figure (for parameters, see text). The activation energy $E$, of $E \approx 35 \mathrm{~cm}^{-1}$ for both molecules, is attributed to an intrinsic low-frequency mode of TEA.

$T^{\alpha}$. The latter form can be obtained by using the specific distribution function for the TLS parameters assumed in Ref. 28. The second term may be a mode either of the guest or of the host, depending on which lies lower in energy. ${ }^{29}$ The second term represents an approximation [see Eq. (3) of Ref. 30] that is valid under the following conditions: (1) the assumption of a one-phonon relaxation of the libration and a weak quadratic coupling of acoustic phonons to this libration in which one term is the phonon coordinate and the other is the vibrational coordinate $\mathrm{e}^{27,31}$; (2) a loose fit of the guest in the glassy host as in Ref. 27 (in crystals ${ }^{24,32,33}$ this condition has been interpreted with the exchange model ${ }^{31}$ as being the case for slow exchange); (3) the activation energy $E$, representing the localized low-frequency mode, having a single value as in crystals ${ }^{24,32-34}$ instead of the Gaussian distribution proposed in Ref. 27. In the low-temperature limit, where $k T \ll E$, the second term on the right-hand side of Eq. (2) will approach the exponential $T$ dependence observed in crystals. $^{24,32,33}$ In amorphous solids, however, where very low activation energies $E \approx k T$ are expected, one should use Eq. (2). ${ }^{30}$

The fits of Eq. (2) to the data of Fig. 7 yield the same parameters for $a$ and $\alpha$ as are obtained with Eq. (1), while $E=33 \pm 3 \mathrm{~cm}^{-1}$ for BChl a in TEA and $35 \pm 3 \mathrm{~cm}^{-1}$ for $\mathrm{H}_{2} \mathrm{P}$ in TEA. Since the activation energy $E$ is similar for both samples, we conclude that an intrinsic low-frequency mode of the host TEA is most probably responsible for the dephasing. In order to prove this, experiments should be performed on TEA doped with guest molecules that do not belong to the same class of porphyrins investigated here. A $T^{1.3}$ behavior combined with an exponential temperature dependence of $\Gamma_{\text {hom }}$ at higher $T$ has also been reported for photon-echo ${ }^{35,36}$ and other hole-burning experiments ${ }^{37,38}$ on various glassy systems. From these experiments, how- ever, it is not clear whether a libration of the guest molecule or some low-frequency modes of the glassy host are responsible for the activation energy.

The question is why the temperature dependence of $\Gamma_{\text {hom }}-\Gamma_{0}$ deviates from a $T^{1.3}$ power law for the systems BChl a and $\mathrm{H}_{2} \mathrm{P}$ in TEA at $T \sim 7 \mathrm{~K}$ and does not do so, for example, for Resorufin in glycerol, at least up to $20 \mathrm{~K}$. From the literature ${ }^{39}$ it is known that glycerol forms hydrogen-bonding networks, yielding a stiff host in which Resorufin is embedded. TEA, on the other hand, is a glass with three ethyl groups that are free to move and do not form a network. We believe that TEA is a softer glass than glycerol at low temperatures, with an intrinsic low-frequency mode of $\sim 35 \mathrm{~cm}^{-1}$ that becomes activated at $T \geq 7 \mathrm{~K}$.

In Fig. 8 holes are reproduced, burned with the broadband cw dye lasers into the $S_{1} \leftarrow S_{0} 0-0$ transitions of $\mathrm{BChl}$ a and $\mathrm{H}_{2} \mathrm{P}$ in TEA. A deep and narrow hole burned resonant with the frequency of the laser appears together with broad side holes on its red side. A side hole at $\sim 20 \mathrm{~cm}^{-1}$ is present in both spectra; we assign this hole to a low-frequency mode of the TEA host. We had expected, however, that the mode active in the dephasing process would have the same frequency as that observed as the side hole in the spectrum, ${ }^{40-42}$ in a way similar to that previously observed in crystals. ${ }^{31-33}$ This is obviously not the

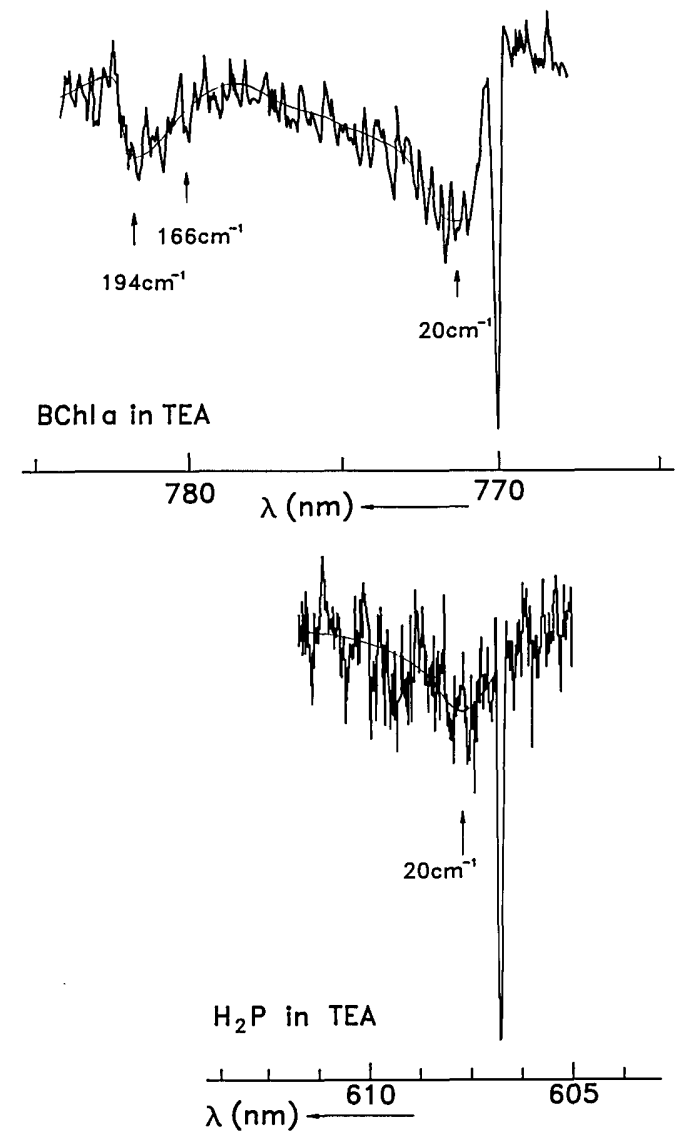

Fig. 8. Holes resonant with the laser and side holes in the $S_{1} \leftarrow S_{0} 0-0$ transition of $\mathrm{BChl}$ a and $\mathrm{H}_{2} \mathrm{P}$ in TEA. The side hole at $\sim 20 \mathrm{~cm}^{-1}$ appears in both spectra and is attributed to a low-frequency mode of the TEA host. The broad, asymmetric side hole observed in the upper spectrum between 160 and $200 \mathrm{~cm}^{-1}$ is assigned to two vibrational modes of BChl a at 166 and $194 \mathrm{~cm}^{-1}$ (see text). 


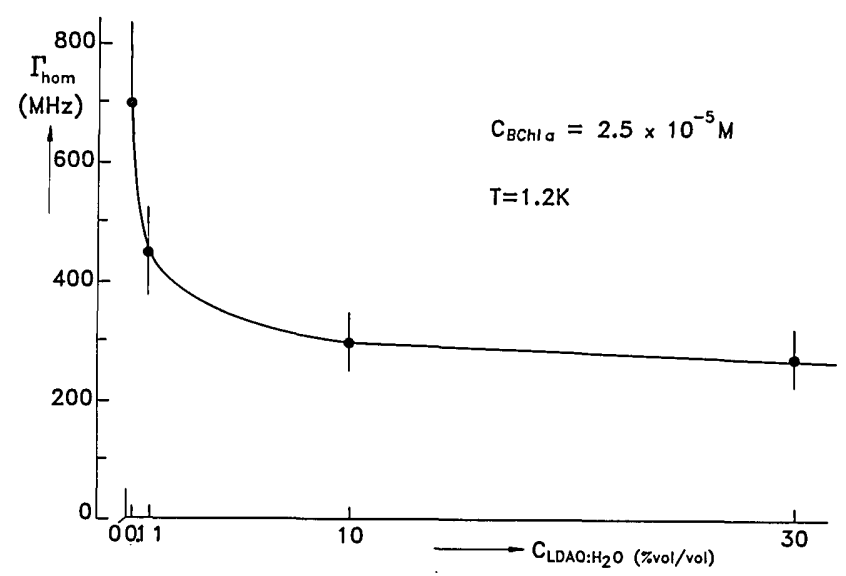

Fig. 9. Homogeneous linewidth $\Gamma_{\text {hom }}$ of the $S_{1} \leftarrow S_{0} 0-0$ transition of $\mathrm{BChl}$ a in LDAO: water micelles as a function of detergent concentration at $1.2 \mathrm{~K}$. The concentration of $\mathrm{BChl}$ a was kept constant.

case here, and we think that TEA probably has more than one low-frequency mode, each of which is active in a different process. By comparison with other dephasing and hole-side-hole experiments, ${ }^{42}$ it appears that the stiffer the glass the higher the temperature at which $\Gamma_{\text {hom }}-\Gamma_{0}$ starts to deviate from a $T^{1.3}$ dependence and the larger the distance between the phonon side hole and the zerophonon hole. In addition to the $20-\mathrm{cm}^{-1}$ side hole, a broad, asymmetric side hole occurs between 160 and $200 \mathrm{~cm}^{-1}$ in the spectrum of BChl a in TEA; we attribute this hole to two vibrational modes of BChl a at 166 and $194 \mathrm{~cm}^{-1}$. These frequencies were previously identified from site-selected spectra in Ref. 12 and were corroborated by us.

\section{Dynamics of Bacteriochlorophyll a in \\ Lauryldimethylamine $\boldsymbol{N}$-oxide Micelles}

As mentioned, detergents are used to isolate pigmentprotein complexes from photosynthetic membranes, and we were intrigued as to whether the detergent influences the pigment dynamics. With this purpose we have studied the interaction of $\mathrm{BChl}$ a with the detergent LDAO at various concentrations of the latter in aqueous solutions. The average number of LDAO molecules in water necessary to form a micelle is $76 .{ }^{43}$ When an impurity, such as $\mathrm{BChl} \mathrm{a}$, is added to the solution or when the detergent concentration is increased, it is likely that this number increases and that therefore the micellar size also increases. The shape of a micelle then changes from spherical to cylindrical. ${ }^{44}$ In the latter case the detergent molecules are more closely packed, which probably leads to a more apolar micelle interior than for low detergent concentrations, for which water may penetrate into the micelle. ${ }^{45}$ At extremely high detergent concentrations multilayered membranes are formed. ${ }^{44}$

We have burned holes at $1.2 \mathrm{~K}$ in the $S_{1} \leftarrow S_{0} 0-0$ transition of $\mathrm{BChl}$ a in four samples with different LDAO: water ratios, with the concentration of $\mathrm{BChl}$ a being kept constant at $2.5 \times 10^{-5} \mathrm{M}$. The resulting homogeneous linewidth as a function of the detergent concentration is plotted in Fig. 9. At a concentration lower than the critical micelle concentration no micelles can be formed, and consequently $\mathrm{BChl}$ a is not dissolved. For this reason we did not use detergent concentrations lower than $0.1 \%$. Notice from Fig. 9 that the value of $\Gamma_{\text {hom }}$ is similar for $30 \%$ and 10\% LDAO: water but strongly increases below $1 \%$. Is this increase caused by pure dephasing, i.e., by a stronger interaction of the individual $\mathrm{BChl}$ a molecules with the surrounding detergent molecules, or by energy transfer between BChl a molecules located in one micelle?

In the customary expression for the homogeneous linewidth, ${ }^{2}$

$$
\Gamma_{\text {hom }}=\left(2 \pi T_{1}\right)^{-1}+\left(\pi T_{2}{ }^{*}\right)^{-1},
$$

the first term on the right-hand side represents the dephasing that is due to the decay of the excited state or to energy transfer between neighboring pigment molecules, which normally does not depend on temperature. The second term, however, is temperature dependent and, as we saw, often follows a $T^{1.3}$ power law in glasses at low temperatures. ${ }^{2}$ In order to determine which of the two terms is responsible for the large $\Gamma_{\text {hom }}$ value found at low LDAO:water concentrations, we studied the temperature dependence of $\Gamma_{\text {hom }}$. The results for $30 \%$ and $0.1 \%$ LDAO between 1.2 and $4.2 \mathrm{~K}$ are shown in Fig. 10 and are compared with those for TEA (see also Fig. 6). In addition, we have plotted the values of $\Gamma_{\text {hom }}$ for $10 \%$ and $1 \%$ LDAO and for dry and wet $\mathrm{CCl}_{4}$ at one temperature, $1.2 \mathrm{~K}$. The temperature dependence of $\Gamma_{\text {hom }}$ again follows a $T^{1.3}$ power law, but the coupling constant $a$ is somewhat larger for $30 \%$ LDAO: water and significantly larger for the $0.1 \%$ LDAO: water sample as compared with that for TEA. It is clear from the results that the higher values of $\Gamma_{\text {hom }}$ obtained for the LDAO:water samples are caused by faster dephasing processes. The extrapolation value of $\Gamma_{\text {hom }}$ for

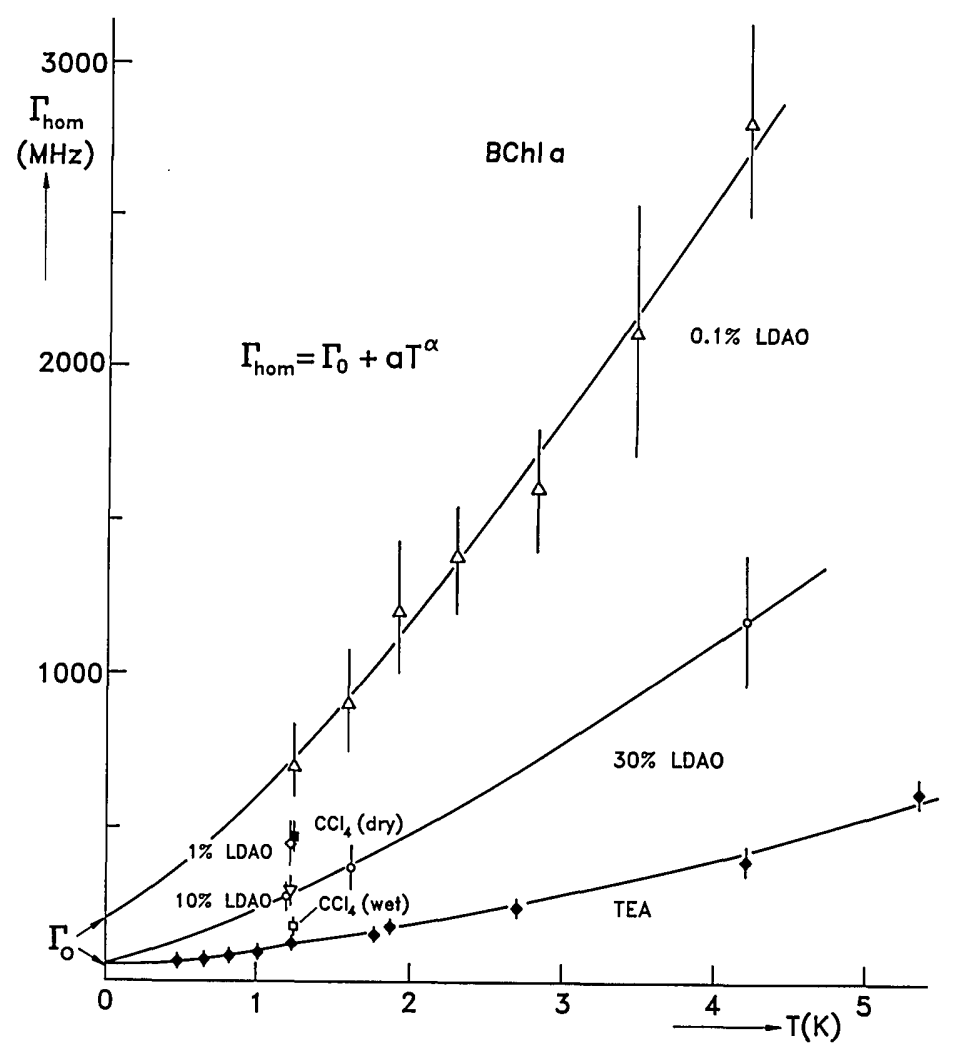

Fig. 10. Homogeneous linewidth $\Gamma_{\text {hom }}$ of the $S_{1} \leftarrow S_{0} 0-0$ transition of $\mathrm{BChl}$ a in $0.1 \%$ and $30 \% \mathrm{LDAO}$ :water, and TEA versus temperature $T$ between 0.4 and $4.2 \mathrm{~K}$. Notice the data points for $1 \%$ and $10 \% \mathrm{LDAO}$ and for wet and dry $\mathrm{CCl}_{4}$ at $1.2 \mathrm{~K}$. The best fit to the data is given by $\Gamma_{\text {hom }}=\Gamma_{0}+a T^{\alpha}$ (for parameters, see text). 
$T \rightarrow 0$ includes, in principle, all temperature-independent deexcitation processes of the excited state and the energy transfer. The fit obtained for $0.1 \%$ LDAO: water yields $\Gamma_{0} \approx 200 \mathrm{MHz}$. This value is subject to a large error, since no reliable $\Gamma_{\text {hom }}$ values could be obtained down to $0.3 \mathrm{~K}$ because of variations in behavior on cooling the micellar samples to liquid-helium temperatures. The short $T_{1}$ value of $0.8 \mathrm{~ns}$, corresponding to $200 \mathrm{MHz}$, may be attributed either to faster decay to the ground state or to a small energy-transfer contribution. Fluorescence experiments and resonance Raman spectra on $\mathrm{BChl}$ a in micelles of octylglucoside at room temperature suggested that the excited-state lifetime of $\mathrm{BChl}$ a is shortened by self-aggregation effects. ${ }^{46}$ If this were also the case in LDAO, then there would probably be no significant energy transfer between $\mathrm{BChl}$ a molecules within a micelle.

The enhanced pure dephasing observed at extremely low detergent concentrations may have two different origins: Either the environment of $\mathrm{BChl}$ a changes, i.e., the micellar shape becomes different at low detergent concentrations, ${ }^{44,47}$ or $\mathrm{BChl}$ a itself within a micelle becomes a slightly different species. The latter change could occur if self-aggregation took place or if complexes of $\mathrm{BChl}$ a with water, (BChl a) $\cdot\left(\mathrm{H}_{2} \mathrm{O}\right)_{n}$, ${ }^{23}$ were formed. In order to shed more light on this problem, we have performed some additional experiments. Holes were burned in a dry BChl a: $\mathrm{CCl}_{4}$ sample, which, according to the literature, should contain dimers, trimers, and maybe even higher self-aggregates of $\mathrm{BChl} \mathrm{a.}{ }^{7,23}$ When water is added to such a sample, disaggregation should occur, and the $\mathrm{BChl}$ a monomers will ligate to one or more water molecules, forming (BChl a) $\cdot\left(\mathrm{H}_{2} \mathrm{O}\right)_{n}$ complexes. $^{23}$ Holes burned in a sample of $\mathrm{BChl}$ a in wet $\mathrm{CCl}_{4}$ at $1.2 \mathrm{~K}$ yielded a value of $\Gamma_{\text {hom }}=150 \mathrm{MHz}$, which is close to the value obtained for BChl a in TEA $\left(\Gamma_{\text {hom }}=100 \mathrm{MHz}\right)$. The implication of this result is that $\left(\mathrm{BChl}\right.$ a) $\cdot\left(\mathrm{H}_{2} \mathrm{O}\right)_{n}$ complexes apparently do not give rise to large broadening like those observed for samples with a low LDAO:water ratio. Holes burned in the dry $\mathrm{CCl}_{4}$ sample yielded $\Gamma_{\text {hom }}=300 \mathrm{MHz}$ at $1.2 \mathrm{~K}$, a value that is of the same order as that found in $1 \%$ LDAO: water samples. We believe that self-aggregation effects are responsible for this larger $\Gamma_{\text {hom }}$ value. If selfaggregation were the only reason for broad holes, one would need a rather large aggregation number of $\mathrm{BChl}$ a molecules in the 0.1\% LDAO:water sample to explain the large value of $\Gamma_{\text {hom }}=750 \mathrm{MHz}$, which seems unlikely, given the very low concentration of $\mathrm{BChl}$ a molecules $\left(c=2.5 \times 10^{-5} \mathrm{M}\right)$. From our results in the wet and dry $\mathrm{CCl}_{4}$ samples we conclude that the high $\Gamma_{\text {hom }}$ value for $\mathrm{BChl}$ a in very dilute $(0.1 \%) \mathrm{LDAO}$ : water samples probably has to be attributed to a combination of two effects. On the one hand, some self-aggregation may occur (compare $\Gamma_{\text {hom }}$ values in $1 \% \mathrm{LDAO}$ and dry $\mathrm{CCl}_{4}$ ) and, on the other hand, the surrounding micelle may change its shape or polarity. For example, at very low concentrations the micelle might become more polar if water were indeed to penetrate into the hydrophobic interior. ${ }^{45}$

\section{CONCLUSIONS}

We have demonstrated that a diode laser, when temperature and current controlled, is a most convenient instrument for hole burning in the near-IR region, having a resolution of $50 \mathrm{MHz}$ and continuous tunability over
$200 \mathrm{GHz}$. We are now comparing permanent holes with transient holes burned and probed on a time scale of microseconds by scanning the diode laser at $\sim 300 \mathrm{GHz} / \mathrm{ms} .{ }^{17}$ From this type of experiments we expect to obtain information about spectral diffusion processes caused by structural relaxation of the glass, at least on a time scale between microseconds and minutes.

Results have been obtained for the $S_{1} \leftarrow S_{0} 0-0$ transition of BChl a in various glasses and micelles at $\sim 775 \mathrm{~nm}$. The dephasing in TEA between 0.4 and $15 \mathrm{~K}$ was studied and compared with that of $\mathrm{H}_{2} \mathrm{P}$ in TEA in the same temperature regime. As for other organic glassy systems, the homogeneous linewidth $\Gamma_{\text {hom }}$ follows a $T^{1.3 \pm 0.1}$ power law for $T<7 \mathrm{~K}$ but deviates toward an exponential dependence at $T \geqslant 7 \mathrm{~K}$. Since a similar behavior has been found for both samples, we conclude that an intrinsic low-frequency mode of $\sim 35 \mathrm{~cm}^{-1}$ of the TEA glass is responsible for the additional dephasing above $7 \mathrm{~K}$.

From site-selected fluorescence spectra at $4.2 \mathrm{~K}$ the vibrational frequencies of the $S_{1}$ state of $\mathrm{BChl}$ a have been corroborated. ${ }^{12}$ The frequencies below $200 \mathrm{~cm}^{-1}$ have also been observed in a hole-side-hole experiment. In such an experiment we have identified a low-frequency mode of $20 \mathrm{~cm}^{-1}$, which also appeared as a side hole in the spectrum of $\mathrm{H}_{2} \mathrm{P}$. We have attributed it to an intrinsic mode of TEA. The fact that two different low-frequency modes are observed, one at $20 \mathrm{~cm}^{-1}$ in the spectra and another at $35 \mathrm{~cm}^{-1}$ in the dephasing, leads us to believe that TEA has more than one such intrinsic mode, each of them active in a different process.

From the dephasing of BChl a in micelles of the detergent LDAO at various concentrations in water and from a comparison of the results with those obtained in wet and dry $\mathrm{CCl}_{4}$, we conclude that self-aggregates of $\mathrm{BChl}$ a are most probably formed within these micelles and that, in addition, appreciable conformational changes of the micelle itself occur at low LDAO concentrations.

\section{ACKNOWLEDGENTS}

We thank J. Th. G. Overbeek (University of Utrecht, The Netherlands) and R. Lipowsky (Institut für Festkörperforschung, Jülich, Germany) for enlightening discussions on the subtleties of micelles and J. H. van der Waals for critical comments on the manuscript. The investigations were supported by the Netherlands Foundation for Physical Research (FOM) and Chemical Research (SON), with financial aid from the Netherlands Organization for Scientific Research (NWO).

\section{REFERENCES}

1. R. I. Personov, in Spectroscopy and Excitation Dynamics of Condensed Molecular Systems, V. M. Agranovich and R. M. Hochstrasser, eds. (North-Holland, Amsterdam, 1983), p. 555, and references therein.

2. S. Völker in Relaxation Processes in Molecular Excited States, J. Fünfschilling, ed. (Kluwer, Dordrecht, The Netherlands, 1989), p. 113, and references therein; Annu. Rev. Phys. Chem. 40, 499 (1989), and references therein.

3. J. C. Goedheer, in The Chlorophylls, L. P. Vernon and G. R. Seely, eds. (Academic, New York, 1966), p. 147; J. Oelze, in Methods in Microbiology (Academic, New York, 1985), Vol. 18, p. 257, and references therein.

4. H. van der Laan, Th. Schmidt, R. W. Visschers, K. J. Visscher, R. van Grondelle, and S. Völker, Chem. Phys. Lett. 170, 231 (1990). 
5. See M. E. Michel-Beyerle, ed., Antennas and Reaction Centers of Photosynthetic Bacteria, Vol. 42 of Springer Series in Chemical Physics, (Springer-Verlag, Berlin, 1985).

6. K. Sauer, J. R. Linday Smith, and A. J. Schulz, J. Am. Chem. Soc. 88, 2681 (1966).

7. T. A. Evans and J. J. Katz, Biochim. Biophys. Acta 396, 414 (1975).

8. J. Gottstein and H. Scheer, Proc. Natl. Acad. Sci. USA 80, 2231 (1983); A. Scherz and W. W. Parson, Biochim. Biophys. Acta 766, 653 (1984); A. Scherz and V. Rosenbach-Belkin, Proc. Natl. Acad. Sci. USA 86, 1505 (1989).

9. J. S. Connolly, E. B. Samuel, and A. F. Janzen, Photochem, Photobiol. 36, 565 (1982), and references threrein.

10. R. A. Avarmaa and K. K. Rebane, Spectrochim. Acta 41A, 1365 (1985).

11. T. P. Carter and G. J. Small, Chem. Phys. Lett. 120, 178 (1985).

12. I. Renge, K. Mauring, and R. Avarmaa, J. Lumin. 37, 207 (1987).

13. K. Iriyama, N. Ogura, and A. Takamiya, J. Biochem. 76, 901 (1974); K. Iriyama, M. Yoshiura, T. Ishii, and M. Shiraki, J. Liq. Chrom. 4, 533 (1981).

14. K. Ballschmiter, T. M. Cotton, H. H. Strain, and J. J. Katz, Biochim. Biophys. Acta 180, 347 (1969).

15. J. Lawrenz and K. Niemax, Spectrochim. Acta 44B, 155 (1989), and references therein; F. Wittgrefe, M. D. Hoogerland, and J. P. Woerdman, Meas. Sci. Technol. 2, 304 (1991).

16. P. Pokrowsky, W. Zapka, F. Chu, and G. C. Bjorklund, Opt. Commun. 44, 175 (1983).

17. R. Wannemacher, H. E. Smorenburg, Th. Schmidt, and S. Völker, "Transient hole-burning with a diode laser," J. Lumin. 53 (to be published).

18. D. Welford and A. Mooradian, Appl. Phys. Lett. 40, 560 (1982).

19. W. A. Hamel and J. P. Woerdman, Phys. Rev. Lett. 64, 1506 (1990).

20. W. A. Hamel, "Effect of outcoupling on the quantum-limited linewidth of a semiconductor laser," Ph.D. dissertation (University of Leiden, Leiden, The Netherlands, 1991), Chap. 6.

21. H. P. H. Thijssen, R. E. van den Berg and S. Völker, Chem. Phys. Lett. 103, 23 (1983); Chem. Phys. Lett. 120, 503 (1985), and references therein.

22. R. van den Berg, A. Visser, and S. Völker, Chem. Phys. Lett. 144, 105 (1988), and references therein.

23. J. J. Katz, L. L. Shipman, T. M. Cotton, and T. R. Janson, in The Porphyrins, D. Dolphin, ed. (Academic, New York, 1978), Vol. 5, p. 401, and references therein.

24. A. I. M. Dicker, L. W. Johnson, S. Völker, and J. H. van der Waals, Chem. Phys. Lett. 100, 8 (1983).

25. P. W. Anderson, B. I. Halperin, and C. M. Varma, Philos. Mag. 25, 1 (1972); W. A. Phillips, J. Low Temp. Phys. 7, 351 (1972).
26. S. Völker, R. M. Macfarlane, A. Z. Genack, H. P. Trommsdorff, and J. H. van der Waals, J. Chem. Phys. 67, 1759 (1977).

27. B. Jackson and R. Silbey, Chem. Phys. Lett. 99, 331 (1983).

28. R. Jankowiak and G. J. Small, Science 237, 618 (1987).

29. A. Elschner, L. R. Narasimhan, and M. D. Fayer, Chem. Phys. Lett. 171, 19 (1990).

30. H. P. H. Thijssen and S. Völker, J. Chem. Phys. 85, 785 (1986).

31. R. M. Shelby, C. B. Harris, and P. A. Cornelius, J. Chem. Phys. 70, 34 (1979).

32. S. Völker, R. M. Macfarlane, and J. H. van der Waals, Chem. Phys. Lett. 53, 8 (1978).

33. A. I. M. Dicker, J. Dobkowski, and S. Völker, Chem. Phys. Lett. 84, 415 (1981).

34. T. J. Aartsma and D. A. Wiersma, Chem. Phys. Lett. 42, 520 (1976); W. H. Hesselink and D. A. Wiersma, J. Chem. Phys. 73, 648 (1980); L. W. Molenkamp and D. A. Wiersma, J. Chem. Phys. 80, 3054 (1984).

35. D. W. Pack, L. R. Narasimhan, and M. D. Fayer, J. Chem. Phys. 92, 4125 (1990); S. R. Greenfield, Y. S. Bai, and M. D. Fayer, Chem. Phys. Lett. 170, 133 (1990), and references therein.

36. H. Fidder, S. de Boer, and D. A. Wiersma, Chem. Phys. 139, 317 (1989); H. C. Meijers and D. A. Wiersma, Chem. Phys. Lett. 181, 312 (1991).

37. M. Berg, C. A. Walsh, L. R. Narasimhan, K. A. Littau, and M. D. Fayer, J. Chem. Phys. 88, 1564 (1988).

38. Th. Basché and C. Bräuchle, Chem. Phys. Lett. 181, 179 (1991).

39. R. Dorsinville, W. M. Franklin, N. Ockman, and R. R. Alfano, Chem. Phys. Lett. 92, 100 (1982).

40. B. L. Fearey, T. P. Carter, and G. J. Small, J. Phys. Chem. 87, 3590 (1983); R. van den Berg and S. Völker, Chem. Phys. 128, 257 (1988).

41. S. Saikan, Y. Kanematsu, R. Shiraishi, T. Nakabayaski, and T. Kushida, J. Lumin. 38, 15 (1987); S. Saikan, T. Kishida, Y. Kanematsu, H. Aota, A. Harada, and M. Kamachi, Chem. Phys. Lett. 166, 358 (1990).

42. H. P. H. Thijssen, R. van den Berg, and S. Völker, Chem. Phys. Lett. 97, 295 (1983).

43. "A guide to the properties and uses of detergents in biology and biochemistry" (Calbiochem Corporation, San Diego, Calif., 1988).

44. J. N. Israelachvili, in Intermolecular and Surface Forces (Academic, London, 1985), p. 244, and references therein.

45. F. M. Menger, Acc. Chem. Res. 12, 111 (1979); H. Wennerström and B. Lindman, J. Phys. Chem. 83, 2931 (1979).

46. M. C. Chang, P. M. Callahan, P. S. Parkes-Loach, T. M. Cotton, and P. A. Loach, Biochemistry 29, 421 (1990).

47. J. Th. G. Overbeek, University of Utrecht, Utrecht, The Netherlands (personal communication, May 1991). 